\title{
For Love or for Money: Intrinsic and extrinsic value congruence in recruitment
}

\section{Arne Vanderstukken*, Anja Van den Broeck**** and Karin Proost*****}

\author{
*Department of Work and Organization Studies, KU Leuven, Belgium. arne.vanderstukken@kuleuven.be \\ **North West University, South Africa \\ ****Open University, The Netherlands
}

\section{Introduction}

O rganizations often struggle with the question of how to attract highly qualified job seekers (Backhaus \& Tikoo, 2004). Becoming the employer of choice is essential, as organizations that are champion at luring the best job seekers likely have the best final hiring options, and, therefore, achieve a competitive advantage (Michaels, HandfieldJones, \& Axelrod, 2001). The importance of attracting good job seekers recently started reaching new heights due to evolutions on the labor market: The retiring baby boom cohort is being replaced by a much smaller generation, creating a scarcity in qualified job seekers and preluding a resurgence of the war for talent (Beechler \& Woodward, 2009). Qualified job seekers thus become harder to find, and are, therefore, even more valuable.

Because of the importance of attracting qualified job seekers, research on possible determinants of applicant attraction has been popular for years. Notable foci in this line of research include job and organization characteristics, usually presented in job advertisements (for an overview, see Uggerslev, Fassina, \& Kraichy, 2012). Based on these characteristics, it is assumed that job seekers attribute a certain identity to organizations, that is, a consistent total of intangible features (Lievens \& Highhouse, 2003). This identity roughly falls into one of two categories: a respectable (e.g., empathic) identity or an impressive (e.g., dominant) identity (Highhouse, Thornbury, \& Little, 2007). The attractiveness of these identities to job seekers depends on their potential to increase the self-esteem of the employees working there (Ashforth \& Mael, 1989).

We add to this literature by pointing out that job seekers are attracted to a certain organizational identity, not only because working there would make them look good, but also because the identity would blend in with their own personal values (Vignoles, Regalia, Manzi, Golledge, \& Scabini, 2006), an assumption which is based on the notion of value congruence in the personorganization fit literature (Johnson \& Jackson, 2009; Kristof-Brown, Zimmerman \& Johnson, 2005). We argue that the distinction between respectable and impressive organizational identities mirrors self-determination theory's (SDT) dichotomy between intrinsic (e.g., selfdevelopment and relatedness) and extrinsic work values (e.g., financial success and status; Kasser \& Ryan, 1996, Vansteenkiste et al., 2007), and hereby launch an innovative approach to value congruence. Specifically, we propose that job seekers who attach high importance to 
intrinsic values, compared to those who attach low importance to these values, are more strongly attracted by signals of respectable organizations, and that extrinsically oriented job seekers are more strongly attracted by signals of impressive organizations than job seekers who attach little importance to these values. This is because, in both cases, the signals promise a work environment that matches the personal values.

By examining the attractiveness of respectable and impressive organizations through the lens of value congruence, the contributions of this study are threefold. First, we contribute to the body of literature providing theoretical and practical insights on which information is most attractive in recruitment, and to whom (e.g., Boswell, Roehling, LePine, \& Moynihan, 2003; Cable \& Turban, 2003; Chapman, Uggerslev, Carroll, Piasentin, \& Jones, 2005; Uggerslev et al., 2012). Second, we add to recruitment research by integrating established theoretical frameworks to explain the appeal of certain signals in recruitment messages, hereby answering the call for a more theory-driven approach in recruitment research (Breaugh \& Starke, 2000). Third, we contribute to SDT (Deci \& Ryan, 2000), as we are among the first to examine the distinction between intrinsic and extrinsic personal values in the recruitment context (for a notable exception, see: Van den Broeck, Vansteenkiste, Lens, \& De Witte, 2010).

This article is structured as follows: first, we investigate how organizational identities are formed from signals in recruitment messages. Second, we take into consideration individual differences regarding SDT's work values, and their potential effects on the attractiveness of organizational identities, in line with the value congruence paradigm.

\section{Job advertisements and inferred organizational identities}

In recruitment, organizations typically adopt strategies aimed at communicating an attractive image to job seekers (Backhaus \& Tikoo, 2004). The effects of these recruitment strategies on the attractiveness of an organization in the eyes of job seekers are often explained through signaling theory (Spence, 1973). In general, signaling theory describes behavior in case of an information asymmetry between two parties such as individuals and organizations (Connelly, Certo, Ireland, \& Reutzel, 2011). One party, the sender, holds information about itself which is unknown to the other party, and chooses whether and how to communicate this information. The other party, the receiver, chooses how to interpret this information, and uses it to assess the quality of the sender. For several reasons, the sender may choose to communicate only a part of the desired information (e.g., sending information is costly). In this case, the receiver is forced to make inferences about the missing information based on the chunks that are available (Spence, 1973).

In terms of recruitment, following signaling theory, an organization may thus use the contents of its recruitment messages to reveal valuable information about itself (Backhaus \& Tikoo, 2004). From the job seeker's point of view, the content of recruitment messages evokes incomplete schemas about the organization (Bangerter, Roulin, \& König, 2012). These schemas then serve an inferential purpose by filling in gaps due to missing information in the image of the organization (Crocker, Fiske, \& Taylor, 1984). In short, job seekers try to find out what to expect from an organization by combining explicitly communicated and inferred information. The relative attractiveness of information in job advertisements, therefore, depends on the comparative appeal of the resulting schemas in the minds of job seekers. These schemas are adjusted and completed over time as additional information seeps in through recruitment, selection, and socialization (Rousseau, 2001).

In general, schemas regarding organizations consist of instrumental features and symbolic features (Lievens \& Highhouse, 2003). Instrumental features are the tangible conditions for employment such as pay, benefits and opportunities for training and development, and are often explicitly communicated by the organization. Symbolic features, in contrast, are the inferred traits or the identity of the organization, and account for incremental variance over the instrumental features. Lievens and Highhouse (2003) argue that, for determining attraction in recruitment, symbolic features may be even more important than instrumental features, because the latter do not differ substantially between competing organizations. To summarize, when job seekers compare organizations and try to decide where to apply, they mainly inspect job advertisements for content that signals attractive symbolic features, that is, an attractive identity of the organization.

Expanding on this symbolic attraction, organizational identities fall into two broad categories, that is, respectable and impressive organizations (Highhouse et al., 2007). Respectable organizations are characterized by sustainable and family-friendly human resource policies. Corporate social responsibility is at the top of their priority list, and they are known for taking good care of their employees. Market signals of this identity, therefore, include supportive work-environments, training opportunities, and so forth. Impressive organizations, in contrast, offer high payment and are prestigious. They are similar to Fortune 500 firms, and proud themselves of being innovative and progressive. Accordingly, an impressive identity is signaled through above-average compensation, promises of prestige, and so forth. Highhouse et al. (2007) explain the attractiveness of both organizational identities by investigating how they could contribute to the job seeker's self-esteem. They argue that being part of an impressive organization gives one an image of being highly competent and worthy of respect, and that being 
part of a respectable organization gives one an image of being good and wholesome. Both situations are attractive to job seekers because they allow one to look good in the eyes of their peers.

Although the need for self-esteem is undoubtedly an influential motive for attraction toward a certain organizational identity, it is likely not the only motive (Vignoles et al., 2006). Therefore, in this article, we advance the possibility that the attraction toward impressive or respectable organizational identities is also driven by the need for self-continuity, that is, the desire to be part of an organization which blends in with other parts of the personal identity (Vignoles et al., 2006). As values make up an important part of the personal identity, this article is linked to the idea of value congruence from personorganization fit literature (Kristof-Brown et al., 2005).

\section{Attractive symbolic features: The role of work values}

Personal values are an important part of a person's selfreported identity (Rokeach, 1973). They are traditionally defined as 'enduring beliefs that a specific mode of conduct or end-state of existence is personally or socially preferable to an opposite or converse mode of conduct or endstate' (p. 5). Applied to the work context, people who value different aspects of their work, are likely to behave differently and chose different things in accordance with their values. Theoretically, SDT (Deci \& Ryan, 2000) argues that work values may be examined in terms of two categories, namely intrinsic work values and extrinsic work values (Vansteenkiste et al., 2007). People who pursue intrinsic work values attach importance to challenges at work through which they can grow and learn. They strive to have warm social relationships with colleagues, and want to make meaningful contributions to society (Vansteenkiste et al., 2007). According to SDT, this tendency is innate and universal, as people are born with an aptitude to develop themselves, to realize their inherent potential and to blend in with social structures (Deci \& Ryan, 2000). People may, however, also develop the tendency to impress others and acquire external signs of worth, that is, to stress the importance of extrinsic work values, such as status, power, and financial rewards (Vansteenkiste et al., 2007). Although such an extrinsic value orientation goes against their inherent growth orientation, extrinsically oriented people may experience fleeting feelings of joy as a consequence of pursuing extrinsic values.

Having intrinsic and/or extrinsic work values gives job seekers a strong sense of what kind of worker they want to be. As a consequence, these values may determine to which organizations job seekers feel attracted. Specifically, based on the value congruence paradigm, job seekers are attracted toward organizations which provide a certain level of fit, that is, a compatibility between the job seeker's values and the (assumed) identity of the future employer (Johnson \& Jackson, 2009; Kristof-Brown et al., 2005). Indeed, when job seekers enter an organization, the membership of that organization becomes an important part of their own identity (Ashforth \& Mael, 1989). In case of value congruence, this new part of the identity does not clash with older parts (i.e., their intrinsic and/or extrinsic work values), and therefore, ensures a sense of self-continuity (Vignoles et al., 2006). The former job seekers have the feeling that they are still the same people, and that they acted in a way that is typical for them. When the organizational identity does not match that of the individual, in contrast, the former job seekers are left with conflicting selfconcepts, a highly stressful situation which is likely to result in turnover (Kristof-Brown et al., 2005, Steele, 1988).

Building on this assumption, we argue that organizations signaling a respectable identity will mostly attract intrinsically oriented job seekers. Indeed, through their recruitment messages, these organizations project their interest in creating a caring and supportive work environment (Highhouse et al., 2007). Intrinsically oriented job seekers anticipate that the membership of such a respectable organization becomes part of their identity, judge that this part blends in perfectly with their focus on personal growth, meaningful contributions to society, and fulfilling social relationships (Vansteenkiste et al., 2007), and therefore, prefer to be employed in a respectable organization. They positively evaluate the respectable organization and pursue employment there. Job seekers who do not share these intrinsic values, in contrast, do not have the feeling that the organization fits with their other self-concepts and, therefore, do not feel attracted.

Hypothesis 1: Signals of a respectable identity are more attractive (Hypothesis 1a) and elicit more pursuit intentions (Hypothesis 1b) among job seekers pursuing intrinsic work values than among job seekers pursuing less intrinsic work values.

Similarly, we expect that organizations projecting an impressive identity will mostly attract extrinsically oriented job seekers. The organizational identity of being dominant and successful (Highhouse et al., 2007) matches the job seekers' preference for status, power, and financial rewards (Vansteenkiste et al., 2007), again resulting in a consistent total of self-concepts and, therefore, attraction toward the organization. Moreover, job seekers without such values are not moved by this kind of organization.

Hypothesis 2: Signals of an impressive image are more attractive (Hypothesis 2a) and elicit more pursuit intentions (Hypothesis 2b) among job seekers pursuing extrinsic work values than among job seekers pursuing less extrinsic work values. 


\section{Method}

\subsection{Sample and procedure}

To test the hypotheses, we conducted a vignette study on 188 business administration students $\left(M_{\text {age }}=21.16\right.$, $S D=1.28)$. The students were asked to complete the study during a break in the middle of class. First, participants completed a questionnaire on their work values. Second, they were randomly presented with one of two fictional job advertisements, in which contents were manipulated (between-subjects design). In the impressive identity condition $(n=93)$, the advertisement referred to: 'You will find yourself in an ambitious job, for which you will receive a handsome reward.' In the respectable identity condition $(n=95)$, this statement was replaced by: 'You will find yourself in a job which allows for a lot of learning experiences. You will work with an agreeable team.' These are documented signals for their respective organizational identities (Highhouse et al., 2007). Except for these statements, both job ads were identical. After reading the job ad, the participants completed a questionnaire on the attractiveness of the job described in the advertisement, their job pursuit intentions, and demographic characteristics.

\subsection{Measures}

\subsubsection{Work values}

Intrinsic and extrinsic work values were measured with a questionnaire by Van den Broeck, Schreurs, Guenter, and van Emmerik (2015). Intrinsic work values were measured with four items, such as 'How important is it for you to have a job in which you can develop yourself?' The items were scored on a 5 -point Likert-type scale ranging from 1 (= not at all important) to 5 (= very important). Cronbach's $\alpha$ of the scale was .74. Extrinsic work values were also measured with four items, such as 'How important is it for you to have a job which grants you financial success?', using the same five point Likert-type scale. Cronbach's $\alpha$ was .82.

\subsubsection{Attraction}

Attraction was measured with four items based on the scale by Highhouse, Lievens, and Sinar (2003). A sample items is: 'This student job is very appealing to me.' The items were scored on a 5-point Likert-type scale ranging from 1 (= strongly disagree) to 5 (= strongly agree). Cronbach's $\alpha$ of this scale was .91.

\subsubsection{Job pursuit intentions}

Job pursuit intentions were measured with three items, based on the scale by Highhouse et al. (2003). A sample item is: 'If this company invited me for a job interview, I would go.' All items were scored on a 5-point Likert-type scale ranging from 1 (= strongly disagree) to 5 (= strongly agree). Cronbach's $\alpha$ of this scale was .73. In the original scale, job pursuit intentions were treated as a subscale of attraction (Highhouse et al., 2003). According to the theory of planned behavior, however, these concepts should be treated as related but separate constructs (Ajzen, 1991). We, therefore, join the group of recruitment researchers that follow this logic (e.g., Chapman et al., 2005).

\subsection{Analyses}

To test the hypotheses, we conducted two moderated hierarchical regression analyses, one for each dependent variable (i.e., attraction and job pursuit intention). In the first step of the regression analysis, we entered the categorical condition parameter (impressive identity condition vs. respectable identity condition, coded as 0 and 1 , respectively) and both personal value orientations (intrinsic work values and extrinsic work values). In the second step, we entered the interaction terms between the condition parameter and intrinsic work values, and between the condition parameter and extrinsic work values. The work values were centered before creating the interaction terms (Aguinis, 2004).

\section{Results}

\subsection{Preliminary analyses}

As shown in the correlation table (Table 1), intrinsic work values and extrinsic work values were positively related. This is not uncommon in SDT research (e.g., Vansteenkiste et al., 2007). As expected, the correlation between attraction and job pursuit intentions was highly significant, indicating that the outcome variables are distinct but closely related.

\subsection{Primary analyses}

Building on value congruence and SDT, Hypothesis 1 stated that job ads signaling a respectable organizational identity would elicit more attraction (Hypothesis 1a) and job pursuit intentions (Hypothesis 1b) among job seekers pursuing intrinsic values, as compared to less intrinsically oriented job seekers. However, as detailed in Table 2, neither the main effect of intrinsic work values, nor the interaction effect of condition and intrinsic work values, were significant for attraction. The analyses on job pursuit intention yielded the same (nonsignificant) results. Hence, we found no support for Hypothesis 1.

In Hypothesis 2, we expected that job ads signaling an impressive image would elicit more attraction (Hypothesis $2 a$ ) and job pursuit intentions (Hypothesis $2 b$ ) among job seekers pursuing extrinsic values as compared to less extrinsically oriented job seekers. This prediction was 
Table 1. Summary of means, standard deviations, and correlations between condition, work values, attraction, and pursuit intention (scale reliabilities are shown on the diagonal)

\begin{tabular}{llllllll}
\hline Variable & $M$ & $S D$ & 1 & 2 & 3 & 4 & 5 \\
\hline $\begin{array}{l}\text { Condition } \\
\text { 1. IIC (0) versus }\end{array}$ & 0.51 & .50 & & & & \\
$\quad$ RIC (1) & & & & & & \\
Work values & & & & & & \\
2. EWV & 3.49 & .78 & -.04 & $(.82)$ & & \\
3. IWV & 4.24 & .61 & -.01 & $.30^{*}$ & $(.74)$ \\
Outcomes & & & & & & & \\
$\quad$ 4. Attraction & 2.62 & .95 & -.12 & -.02 & -.09 & $(.91)$ \\
5. Pursuit intention & 2.97 & 1.01 & -.05 & -.05 & -.08 & $.76^{*}(.73)$ \\
\hline
\end{tabular}

Note: ${ }^{*} p<.01$. IIC $=$ impressive identity condition; $\mathrm{RIC}=$ respectable identity condition; $\mathrm{EWV}=$ extrinsic work values; IWV = intrinsic work values.

Table 2. Regression coefficients of condition, work values and interactions on attraction and pursuit intentions

\begin{tabular}{|c|c|c|c|c|c|c|c|c|}
\hline \multirow[b]{2}{*}{ Predictor } & \multicolumn{2}{|c|}{ Step 1} & \multicolumn{2}{|c|}{ Step 2} & \multicolumn{2}{|c|}{ Step 1} & \multicolumn{2}{|c|}{ Step 2} \\
\hline & $B$ & $p$ & $B$ & $p$ & $B$ & $p$ & $\bar{B}$ & $p$ \\
\hline (Constant) & 3.32 & .00 & 3.01 & .00 & 3.62 & .00 & 3.40 & .00 \\
\hline $\begin{array}{l}\text { IIC }(0) \text { versus } \\
\operatorname{RIC}(1)\end{array}$ & -.22 & .11 & -.17 & .23 & -.11 & .48 & -.07 & .65 \\
\hline EWV & .01 & .93 & $.22 \dagger$ & .09 & -.03 & .73 & .11 & .47 \\
\hline IWV & -.14 & .23 & -.25 & .12 & -.11 & .37 & -.17 & .31 \\
\hline $\begin{array}{l}\text { IIC versus } \\
\quad \mathrm{RIC} \times \mathrm{EWV}\end{array}$ & & & $-.33 *$ & .02 & & & -.22 & .16 \\
\hline $\begin{array}{l}\text { IIC versus } \\
\text { RIC } \times I W V\end{array}$ & & & .04 & .77 & & & .02 & .92 \\
\hline & .02 & & .05 & & .01 & & .02 & \\
\hline$R^{2}$ change & & & $.03+$ & .06 & & & .01 & .36 \\
\hline
\end{tabular}

Note: $t_{p}<.10 ; \quad * p<.05 . \quad$ IIC $=$ impressive identity condition; $\mathrm{RIC}=$ respectable identity condition; EWV = extrinsic work values; $\mathrm{IWV}=$ intrinsic work values.

partially confirmed, as the interaction term of condition and extrinsic work values significantly predicted attraction (Hypothesis 2a, Table 2). The interaction term had a negative value, meaning that in the impressive identity condition, extrinsic personal values were more positively related to attraction than in the respectable identity condition. In other words, the interaction effect was in line with our expectations. Moreover, the main effect of extrinsic work values was marginally significant and positive. Therefore, we consider Hypothesis 2a supported. Concerning Hypothesis $2 b$, however, no significant effect of the interaction parameter on pursuit intention was found (Table 2). Therefore, no support for Hypothesis $2 b$ was found, leaving Hypothesis 2 only partially supported.

\section{Discussion}

The main aim of this study was to examine the relative effectiveness of impressive and respectable organizational identities, in terms of attracting job seekers and persuading them to apply for the job. Focusing on self-continuity and the literature on value congruence, we took into account individual differences regarding intrinsic and extrinsic work values. Specifically, we argued that intrinsic work values would predict attraction and pursuit intentions toward respectable organizations, and that extrinsic work values would predict attraction and pursuit intentions toward impressive organizations.

The hypotheses pertaining to attraction were only partially confirmed. No support for value congruence in terms of intrinsic values was found: People reporting intrinsic values did not find the respectable organization more attractive, compared to less intrinsically oriented job seekers. Although joining a respectable organization would fit in perfectly with their self-concept of pursuing intrinsic values, signals of such an identity were not found to be more attractive. We can see several possible explanations for this result. First, the result may only pertain to the initial attraction toward the organization. According to Beach (1993), job seekers' decision processes can be partitioned in a screening phase and a choice phase. During the screening phase, job seekers narrow down the choice alternatives to a more manageable pool of options. The process of selecting the best organizations from the remaining pool, called the choice phase, is usually delayed until more information becomes available. Illustrating this process, Rynes, Schwab, and Heneman (1983) found that most job seekers first investigate if pay and prestige (i.e., signals of an impressive organization) meet predetermined levels. This is usually regarded as a minimum requirement, designed to reduce the pool of options (cf., the screening phase). Nonpecuniary attributes are only considered later on, when choosing where to apply among the remaining options (cf., the choice phase). It is, therefore, possible that the participants in this study were still in the screening phase, inspecting the job ad for pay and prestige and putting their intrinsic work values on hold. Intrinsic values and signals of a respectable organizational identity may gain further importance as the job seeker advances through the recruitment and selection process, that is, into the choice phase. We believe that examining the role of intrinsic values throughout the job seeking process would be a fruitful path for future research.

A second possible reason for the absence of the intrinsic value congruence effect can be sought in signaling theory (Spence, 1973). Not only does signaling theory describe how job seekers interpret signals from organizations to construe mental images, it also predicts the impact of these signals based on signals' properties. Specifically, a signal is ideally hard-to-fake if it is to be treated as honest and reliable (Bangerter et al., 2012). Signals which may very well be fake are interpreted with caution and, therefore, have less impact. It is possible that signals of a respectable organizational identity suffer from such suspicion. Promises of agreeable colleagues and opportunities to develop oneself may come across as vague and can 
only be verified after the socialization process. In other words, job seekers have little guarantee that these promises are genuine, so the organization can easily fake them. As a consequence, job seekers may ignore these easy-tofake signals, omitting them from their evaluation of the organization. On a side note: It may be more difficult to mislead job seekers into believing that the organization is impressive. Pay is mostly presented in the employment contract and, therefore, easily verified, and prestige depends on outsiders' views and is hence easy to verify among colleague job seekers, friends, or family.

Third, the absence of the intrinsic value congruence effect may be attributed to a lack of variance in respondents' intrinsic work values. Indeed, it appears that respondents invariantly indicated high scores on the intrinsic value questionnaire. As a result, the intrinsic value congruence scores also had low variance, which statistically limits the amount of outcome variance they can account for. A replication with a more heterogeneous sample (i.e., including respondents low on intrinsic work values) would be able to solve this potential problem and shed light on this alternative explanation for our nullfinding.

Contrary to intrinsic value congruence, extrinsic value congruence did relate to attraction, thereby supporting our hypothesis. Job ads signaling an impressive organizational identity were more attractive to job seekers pursuing extrinsic values than to less extrinsically oriented job seekers. Presumably, extrinsically oriented job seekers see the impressive job ad as a signal that their selfconcepts will remain consistent after the membership to the organization is internalized. Indeed, adopting the identity of employee in a dominant and well-compensating firm fits perfectly with the existing identity of pursuing status, power, and financial rewards. Based on this result, we can conclude that an organization should signal an impressive identity by offering money and prestige in job advertisements to capture the initial interest of extrinsically oriented job seekers. However, caution is advised when employing this strategy. Above all, recruitment campaigns should paint a realistic picture of the future employment experience. Unrealistic job previews lead to unrealistic expectations, which in turn cause thoughts of quitting in employees (Earnest, Allen, \& Landis, 2011).

While the results on attraction were to some extent as expected, we found no significant effects on job pursuit intentions. This was rather surprising, given that attraction and job pursuit intentions are often assumed to be simultaneously influenced (e.g., Carless, 2005). However, according to the theory of planned behavior (Ajzen, 1991), intentions to perform a certain behavior are not only determined by the attractiveness of the outcomes of that behavior, but also by subjective norms and perceived behavioral control. It is possible that the respondents, being mostly inexperienced students, do not feel that they have control over job pursuit behaviors yet, impeding the transformation of attraction into subsequent behavioral intentions. Moreover, one could again argue that the participants are still in the screening phase of selecting organizations, when applying for a job is still in the distant future. It is, therefore, possible that researchers can only truly gain insight into their pursuit intentions during the choice phase (Beach, 1993).

\subsection{Limitations and future research}

This study has some limitations which may be addressed in future research. The first three limitations pertain to the generalizability of our study, and the fourth concerns the realism of our manipulation.

A first limitation is the use of a student sample to make predictions about attitudes and intentions of job seekers. One could argue that college students cannot be compared with actual job seekers, because college students mostly take on a job to earn some extra money, rather than to pursue a job that fits their interest and capacities (Adriaenssens, Verhaest, Van den Broeck, Proost, \& Berings, 2014). This would mean that students' work drives are by definition extrinsic, regardless of the student's self-reported work values. However, such an extrinsic work drive is mostly found in young students. More mature college students (like the ones in our sample) mostly view a student job as relevant work experience, and thus choose their jobs for career-oriented reasons (Larkin, LaPort, \& Pines, 2007). We, therefore, believe that our study was externally valid, although future research among job seekers may aim to replicate our results.

A related, second limitation pertains to the fact that we presented advertisements for student jobs. This increased psychological realism, as this situation has more ecological validity for students. The potential problem with student job ads is that they promise by definition only short-term employment, which may - again - be chosen because of extrinsic reasons such as having a job at all or accepting a job that increases one's changes to obtain a better job (e.g., a permanent job or a job providing more opportunities to grow) later on (de Jong, De Cuyper, De Witte, Silla, \& Bernhard-Oettel, 2009). Therefore, an interesting route for further research could be to test whether our results can be generalized to temporary nonstudent jobs and whether they are also valid in searching for a permanent job.

A third limitation may be that all our respondents majored in business administration. Because of their major, one may expect a high average, as well as low variance, regarding the extrinsic value orientation in this sample (Vansteenkiste, Duriez, Simons, \& Soenens, 2006). The average respondent, however, pursued intrinsic rather than extrinsic work values $\left(M_{\mathrm{IWV}}=4.24 ; M_{\mathrm{EWV}}=3.49\right.$; $t=12.23 ; p<.01)$. Moreover, the variance in extrinsic 
value orientation was large enough to account for some of the attraction variance. We, therefore, conclude that the statistical properties of extrinsic value orientation do not pose the expected problems for generalization. The variance in intrinsic value orientation, in contrast, was rather low, which one would not expect based on the properties of the sample. Future research may, therefore, want to test our hypotheses on people who are more (or less) oriented toward intrinsic values.

Finally, we presented our participants with job ads containing signals of either a respectable identity or an impressive identity. This allowed us to make a clear distinction and scrutinize the effects of personal values in the attractiveness of both identities. However, actual job ads are likely to contain both types of signals. Future research could, therefore, test how participants would react to the presence of both signals of respectability and impressiveness.

In short, to address these limitations, future research should focus on replicating this study on actual job seekers, looking for long-term employment and pursuing different kinds of work values. Moreover, future research could include job ads containing both respectable and impressive signals, as well as examine possible mediators and moderators of the documented effect, such as the participant's anticipation of self-continuity, and the participant's position in the decision process (screening phase or choice phase). Such additions could provide valuable information on presently latent effects and processes, as well as boundary conditions.

\subsection{Conclusion}

In sum, signals of an impressive organizational identity were the most attractive aspects in the eyes of job seekers attaching high importance to extrinsic values. Signals of a respectable organizational identity, in contrast, were equally attractive for job seekers attaching high or low importance to the associated supplies. This leads us to the conclusion that extrinsic work values explain the appeal of impressive organizations, hereby providing partial support for the applicability of the value congruence paradigm in recruitment.

\section{References}

Adriaenssens, S., Verhaest, D., Van den Broeck, A., Proost, K., \& Berings, D. (2014). De arbeidsparticipatie van Vlaamse scholieren. Tijdschrift voor Arbeidsvraagstukken, 30, 281-301.

Aguinis, H. (2004). Regression analysis for categorical moderators. New York: Guilford.

Ajzen, I. (1991). The theory of planned behavior. Organizational Behavior and Human Decision Processes, 50, 179-211.

Ashforth, B. E., \& Mael, F. (1989). Social identity theory and the organization. Academy of Management Review, 14, 20-39.
Backhaus, K., \& Tikoo, S. (2004). Conceptualizing and researching employer branding. Career Development International, 9, 501-517.

Bangerter, A., Roulin, N., \& König, C. J. (2012). Personnel selection as a signaling game. Journal of Applied Psychology, 97, 719738.

Beach, L. R. (1993). Broadening the definition of decision making: The role of prechoice screening of options. Psychological Science, 4, 215-220.

Beechler, S., \& Woodward, I. C. (2009). The global "war for talent." Journal of International Management, 15, 273-285.

Boswell, W. R., Roehling, M. V., LePine, M. A., \& Moynihan, L. M. (2003). Individual job-choice decisions and the impact of job attributes and recruitment practices: A longitudinal field study. Human Resource Management, 42, 23-37.

Breaugh, J. A., \& Starke, M. (2000). Research on employee recruitment: So many studies, so many remaining questions. Journal of Management, 26, 405-434.

Cable, D. M., \& Turban, D. B. (2003). The value of organizational reputation in the recruitment context: $A$ brand-equity perspective. Journal of Applied Social Psychology, 33, 2244-2266.

Carless, S. A. (2005). Person-job fit versus person-organization fit as predictors of organizational attraction and job acceptance intentions: A longitudinal study. Journal of Occupational and Organizational Psychology,78, 411-429.

Chapman, D. S., Uggerslev, K. L., Carroll, S. A., Piasentin, K. A., \& Jones, D. A. (2005). Applicant attraction to organizations and job choice: A meta-analytic review of the correlates of recruiting outcomes. Journal of Applied Psychology, 90, 928-944.

Connelly, B. L., Certo, S. T., Ireland, R. D., \& Reutzel, C. R. (2011). Signaling theory: A review and assessment. Journal of Management, 37, 39-67.

Crocker, J., Fiske, S. T., \& Taylor, S. E. (1984). Schematic bases of belief change. In J. R. Eiser (Ed.), Attitudinal judgment (pp. 192226). New York, NY: Springer.

Deci, E. L., \& Ryan, R. M. (2000). The "what" and "why" of goal pursuits: Human needs and the self-determination of behavior. Psychological Inquiry, 11, 227-268.

De Jong, J., De Cuyper, N., De Witte, H., Silla, I., \& BernhardOettel, C. (2009). Motives for accepting temporary employment: A typology. International Journal of Manpower, 30, 237252.

Earnest, D. R., Allen, D. G., \& Landis, R. S. (2011). Mechanisms linking realistic job previews with turnover: A meta-analytic path analysis. Personnel Psychology, 64, 865-897.

Highhouse, S., Lievens, F., \& Sinar, E. F. (2003). Measuring attraction to organizations. Educational and Psychological Measurement, 63, 986-1001.

Highhouse, S., Thornbury, E. E., \& Little, I. S. (2007). Social-identity functions of attraction to organizations. Organizational Behavior and Human Decision Processes, 103, 134-146.

Johnson, R. E., \& Jackson, E. M. (2009). Appeal of organizational values is in the eye of the beholder: The moderating role of employee identity. Journal of Occupational and Organizational Psychology, 82, 915-933.

Kasser, T., \& Ryan, R. M. (1996). Further examining the American dream: Differential correlates of intrinsic and extrinsic goals. Personality and Social Psychology Bulletin, 22, 280-287.

Kristof-Brown, A. L., Zimmerman, R. D., \& Johnson, E. C. (2005). Consequences of individuals' fit at work: A meta- 
analysis of person-job, person-organization, person-group, and person-supervisor fit. Personnel Psychology, 58, 281-342.

Larkin, J. E., LaPort, K. A., \& Pines, H. A. (2007). Job choice and career relevance for today's college students. Journal of Employment Counseling, 44, 86-94.

Lievens, F., \& Highhouse, S. (2003). The relation of instrumental and symbolic attributes to a company's attractiveness as an employer. Personnel Psychology, 56, 75-102.

Michaels, E., Handfield-Jones, H., \& Axelrod, B. (2001). The war for talent. Boston, MA: Harvard Business Press.

Rokeach, M. (1973). The nature of human values. New York, NY: Free Press.

Rousseau, D. M. (2001). Schema, promise and mutuality: The building blocks of the psychological contract. Journal of Occupational and Organizational Psychology, 74, 511-541.

Rynes, S. L., Schwab, D. P., \& Heneman III, H. G. (1983). The role of pay and market pay variability in job application decisions. Organizational Behavior and Human Performance, 31, 353-364.

Spence, M. (1973). Job market signaling. The Quarterly Journal of Economics, 87, 355-374.

Steele, C. M. (1988). The psychology of self-affirmation: Sustaining the integrity of the self. Advances in Experimental Social Psychology, 21, 261-302.
Uggerslev, K. L., Fassina, N. E., \& Kraichy, D. (2012). Recruiting through the stages: A meta-analytic test of predictors of applicant attraction at different stages of the recruiting process. Personnel Psychology, 65, 597-660.

Van den Broeck, A., Schreurs, B., Guenter, H., \& Van Emmerik, H. (2015). Skill utilization and well-being: A cross-level story of day-to-day fluctuations and personal intrinsic values. Work \& Stress, 29, 306-324.

Van den Broeck, A., Vansteenkiste, M., Lens, W., \& De Witte, H. (2010). Unemployed individuals' work values and job flexibility: An explanation from expectancy-value theory and selfdetermination theory. Applied Psychology, 59, 296-317.

Vansteenkiste, M., Duriez, B., Simons, J., \& Soenens, B. (2006). Materialistic values and well-being among business students: Further evidence of their detrimental effect. Journal of Applied Social Psychology, 36, 2892-2908.

Vansteenkiste, M., Neyrinck, B., Niemiec, C., Soenens, B., De Witte, H., \& Van den Broeck, A. (2007). On the relations among work value orientations, psychological need satisfaction, and job outcomes: A self-determination theory approach. Journal of Occupational and Organizational Psychology, 80, 251-277.

Vignoles, V. L., Regalia, C., Manzi, C., Golledge, J., \& Scabini, E. (2006). Beyond self-esteem: Influence of multiple motives on identity construction. Journal of Personality and Social Psychology, 90, 308-333. 